\title{
Educar para a compreensão \\ das Ciências da Natureza: \\ discutindo caminhos teórico-metodológicos
}

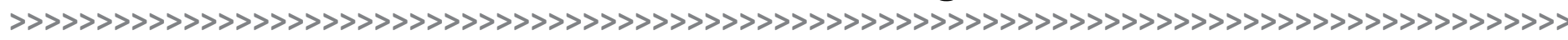

Vania Fernandes e Silva*

Rosângela Veiga Júlio Ferreira**

\begin{abstract}
Resumo:
Este texto objetiva apresentar reflexões sobre o que significa educar para a compreensão das Ciências da Natureza desde os anos iniciais, a partir da (re)estruturação de um currículo que entenda a metodologia da alfabetização científica como forma de possibilitar acesso ao conhecimento científico, podendo ser compreendido em seus limites e potencialidades. Para tanto, defendemos que o acesso a textos informativos e argumentativos, advindos de diferentes fontes, assim como os do campo de atuação artístico-literário, contribui para uma formação leitora que possibilite observar criticamente o mundo. Nessa proposta curricular, o conteúdo passa a ser entendido como meio para a formação de um pensamento sobre essa área do conhecimento. Essa proposta retoma documentos oficiais que orientaram a organização dos currículos desde a década de 1990, tomando como ponto de partida os desafios atuais para a formação de um leitor que adote uma atitude científica.
\end{abstract}

\section{Palavras-chave:}

Ciências da Natureza. Currículo. Anos iniciais. Alfabetização científica. Atitude científica.

\begin{abstract}
:
This paper aims to present reflections on what it means to educate for the understanding of Nature Sciences since the early years, from the (re)structuring of a curriculum that understands the methodology of scientific literacy as a way to enable access to scientific knowledge, can be understood within its limits and potentialities. Therefore, we defend that the access to informative and argumentative, texts coming from different sources, as well as those from the field of artistic literary activity, contributes to a reader training that enables the critical observation of the world. In this curricular proposal, the content starts to be understood as a means for the formation of a thought about this area of knowledge. This proposal takes up official documents that have guided the organization of curricula since the 1990s, taking as a starting point the current challenges for the training of a reader who adopts a scientific attitude.
\end{abstract}

\section{Keywords:}

Nature Sciences. Curriculum. Early years. Scientific literacy. Scientific attitude.

\footnotetext{
* > Doutora em Educação para a Ciência pela Universidade Estadual Paulista (UNESP), Professora de Ciências no Ensino Básico Técnico e Tecnológico (EBTT) do Colégio de Aplicação João XXIII/UFJF, que responde atualmente pela coordenação dos Anos iniciais do Ensino Fundamental na mesma instituição.

E-mail:vaniafernandesesilva@hotmail.com.
}

\footnotetext{
** > Doutora em Educação pela Universidade Federal de Juiz de Fora (UFJF), Professora de Ciências no Ensino Básico Técnico e Tecnológico (EBTT) do Colégio de Aplicação João XXIII/UFJF, que responde atualmente pela coordenação dos Anos iniciais do Ensino Fundamental na mesma instituição. E-mail: rosangela.ferreira@ufjf.edu.br.
} 


\section{Introdução}

O que significa educar para a compreensão das Ciências da Natureza? Como educar numa lógica que considere o que e como a criança pensa as Ciências na relação com o contexto em que vive? Como a escola poderia contribuir para o desenvolvimento de um pensamento sobre o que a criança aprende, considerando o percurso de compreensão? Como os professores poderiam mediar a relação entre conhecimento científico e leitura crítica sobre os fatos, buscando uma formação leitora em que a criança estabeleça relações conceituais, realize inferências, dentre outras estratégias de compreensão? O desafio é o de pensar em como educar para o fomento da atitude científica, promovendo situações de reflexões nas quais seja possível pensar sobre fenômenos naturais, bem como estabelecer contato com as tecnologias.

Essas questões tocam-se em um ponto: como ensinar Ciências Naturais nos anos iniciais do Ensino Fundamental, considerando uma concepção de infância e de ensino que conflua com os princípios de formação do leitor. Partindo dessa inter-relação, defendemos que o currículo deve se pautar em campos do conhecimento científico voltados ao desenvolvimento da alfabetização. A formação do pensamento científico, mediada por múltiplas linguagens e estratégias de ensino voltadas à aprendizagem de conceitos, está baseada na observação, na experimentação e na discussão sobre conhecimentos científicos em prol da melhoria das condições da vida no planeta. Desse modo, entendemos Ciência "[...] como uma linguagem para facilitar nossa leitura do mundo" (CHASSOT, 1993, p. 37), pois, "[...] para fazer uma oposição ao cientificismo, ainda tão marcadamente presente nos dias atuais, especialmente em nossas salas de aula, inclusive nas universidades, insistimos na necessidade de se considerar que essa linguagem é um construto humano, logo mutável e falível" (CHASSOT, 1993, p. 37). Portanto, o ensino de Ciências, nessa perspectiva, visa à compreensão de conhecimentos científicos que contribuam para a formação de cidadãos críticos.

Na busca pela fundamentação de uma concepção de ensino de Ciências que atrela conhecimento científico e formação do leitor, constatamos que a interpretação de documentos oficiais, como as orientações para inclusão da criança de seis anos de idade (BRASIL, 2007), reforça a necessidade de que os estudantes do segmento dos anos iniciais estejam plenamente alfabetizados até o $3^{\circ}$ ano. Isso porque esse documento amplia a noção de linguagem para além do ensino de Língua Portuguesa, ao admitir a organização dos componentes curriculares em áreas de conhecimento, além de pressupor que o trabalho desenvolvido pela escola com os diferentes componentes deve explorar as diversas linguagens, oferecendo oportunidades de exercício da leitura e da escrita.

O documento de caráter normativo, a Base Nacional Comum Curricular (BNCC), homologada em dezembro de 2018, apresentada como atendimento a estratégias das metas 1, 2 e 3 do Plano Nacional de Educação, que versam respectivamente sobre a universalização do ensino na Educação Infantil, Ensino Fundamental e Ensino Médio, dentre outras metas, propõe a antecipação dessa alfabetização plena para o $2^{\circ}$ ano do Ensino Fundamental (BRASIL, 2018).

Independentemente do ano em que as normativas legais definam como orientação para o alcance da alfabetização, entendemos que, para que possamos garantir a todos os estudantes o direito a aprender com qualidade, é necessário que a escola assuma o compromisso de desenvolver metodologias que possibilitem o atendimento aos diferentes ritmos de aprendizagem de forma a articular as áreas do conhecimento.

Note que, nesse processo de articulação, uma concepção de ensino de Ciências pautada na possibilidade de que o estudante se aproprie de um léxico próprio, lendo e compreendendo os textos da área contribui para a formação leitora. Diante de textos com 
informações científicas, ao serem ensinadas estratégias leitoras próprias à compreensão de gêneros do campo de atuação Práticas de Estudos e Pesquisas (BRASIL, 2018, p. 86) ${ }^{1}$, colocam-se em evidência diferentes pontos de vista sobre a produção humana. Textos com diferentes complexidades, do ponto de vista linguístico (FERREIRA; MICARELLO; BARBOSA, 2018), podem ser de fundamental importância para o trabalho de desenvolvimento da alfabetização científica entre leitores iniciantes. Nesse sentido, escolhas estratégicas que considerem a fluência leitora, por exemplo, precisam ser consideradas.

O que argumentamos é que alfabetizar cientificamente, de forma concomitante com a formação leitora, precisa considerar o cruzamento entre teorias da área em estudo, no caso em tela Ciências, e as do desenvolvimento. Isso talvez contribua para que se compreenda que ler cientificamente é possível, mesmo entre leitores menos experientes. Para tanto, defendemos ser necessário pautar escolhas metodológicas em uma concepção de currículo que conflua com a possibilidade de atuar no desenvolvimento, nesse caso, de uma compreensão para as Ciências da Natureza.

Nesse sentido, trazemos à reflexão questões que sustentam a escolha aqui defendida, qual seja, a do currículo como "território movente" (MIRANDA, 2010). Trata-se de um contraponto a definições rígidas/fixas em torno do que ensinar, tomando, portanto, o conteúdo como meio e a definição de estratégias metodológicas como elementos fundamentais para se educar para a compreensão de um "pensamento sobre". Assim, entende-se currículo como escolhas intencionais que orientam a educação do olhar, sendo constituído por: a. com que concepção ensinar; b. para quem ensinar; c. com que objetivo ensinar; $d$. o que ensinar; e. como ensinar.

Há, desse modo, um deslocamento da centralidade em construções historicamente instituídas para a possibilidade de partirmos de questões científicas do presente, no caso do currículo de Ciências da Natureza, para compreender mudanças e/ou permanências de conhecimentos científicos e, consequentemente pensar o futuro das Ciências. Ao atuar no desenvolvimento de um "pensamento sobre", ou seja, uma inteligência sobre o processo de áreas do conhecimento, justifica-se tal deslocamento - o conteúdo deixa de ser o centro e passa a ser o meio sobre o qual a aprendizagem se opera. Noutras palavras, os conteúdos são "territórios moventes", podendo ser retomados sob diferentes pontos de vista na relação com sujeitos, lugares, objetos, conhecimentos, entre outros fatores que nos ajudam a compreender o mundo.

Para defender essa concepção de currículo, que desloca a centralidade do conteúdo para o como aprender, trazemos, neste texto, num primeiro momento, a alfabetização científica, discutindo desafios metodológicos para sua implementação. Na sequência, apresentamos uma proposta curricular que visa a propor reflexões em torno da possibilidade de que a escola pense em como educar para o desenvolvimento da atitude científica. E, nas considerações finais, apontamos que o leitor se alfabetiza também pela apropriação do conhecimento científico, sendo as múltiplas linguagens o compromisso de um currículo concebido na relação com os diferentes tempos dessa formação leitora.

\section{Desafios metodológicos de educar para a atitude científica: o papel da alfabetização científica}

Um dos principais desafios que se enfrenta para a implementação de práticas de ensino que contribuam para o desenvolvimento de uma atitude científica ${ }^{2}$ advém de um "não lugar" para as Ciências da Natureza nos anos iniciais do Ensino Fundamental. Muitas vezes, a centralidade do currículo encontra-se nas chamadas disciplinas tronco - Língua Portuguesa e Matemática. Nesse caso, há uma incompreensão da potência que o ensino de
1 > As práticas de linguagem, na BNCC, são consideradas por meio de "[...] campos de atuação aponta para a importância da contextualização do conhecimento escolar, para a ideia de que essas práticas derivam de situações da vida social e, ao mesmo tempo, precisam ser situadas em contextos significativos para os estudantes" (BRASIL, 2018, p. 86). São eles: vida cotidiana, Artístico-Literário, Práticas de Estudo e Pesquisa e Vida pública.

2 > Apoiamo-nos em Chauí (1998), para cunhar o conceito de atitude científica que definimos como a formação de um pensamento crítico sobre um conhecimento científico que provoca no sujeito uma compreensão ampliada sobre como usar esse conhecimento para entender e mudar o mundo. Significa incorporar uma atitude investigativa diante dos fatos que constituem o cotidiano, pautada na observação curiosa e no questionamento de verdades ou explicações sobre certezas aprendidas no cotidiano. 
Ciências, por exemplo, poderia adquirir para a formação do leitor, contribuindo de forma efetiva para o estabelecimento de relações conceituais e para a dimensão de criticidade. Tal fator nos desafia e nos chama ao compromisso de contribuir para que essa área do conhecimento consiga ser compreendida nas possibilidades de efetivação do currículo dos anos iniciais.

Outro desafio é o de definir uma perspectiva metodológica que contribua para a formação dessa atitude científica, o que nos leva a considerar, no caso em tela, o tema da alfabetização científica, que vem sendo discutido desde a década de 1980 por diferentes estudos $^{3}$, com poucas produções voltadas, especificamente, para os anos iniciais do Ensino Fundamental.

Tomamos como referência conceitos cunhados por autores da área do ensino de Ciências para a defesa de uma concepção para esse conceito tomado como metodologia de ensino. De acordo com Krasilchik e Marandino (2007, p. 19), um sujeito cientificamente alfabetizado é aquele “[...] capaz de não só identificar o vocabulário da ciência, mas também de compreender conceitos e utilizá-los para enfrentar desafios e refletir sobre seu cotidiano". A compreensão do mundo possibilita aos sujeitos que nele vivem questioná-lo. Sendo assim, segundo Chassot (2014, p. 62), “[...] seria desejável que os alfabetizados cientificamente não apenas tivessem facilitada a leitura do mundo em que vivem, mas entendessem as necessidades de transformá-lo, e transformá-lo para melhor”. A nosso ver, ambas as definições complementam-se e desafiam a escola a pensar em um currículo que indique como pode ser possível a um estudante se apropriar de léxicos próprios da área das Ciências, lendo e compreendendo conceitos fundamentais para a formação de um pensamento científico.

Ampliando ainda mais esse ponto de complementaridade entre o que e como ensinar, a partir de qual concepção de ensino, trazemos ao texto as reflexões de Lorenzetti e Delizoicov (2001) que afirmam ser possível alfabetizar cientificamente nos anos iniciais do Ensino Fundamental antes e associadamente com a aprendizagem do código de escrita, de modo a expandir a cultura dos estudantes, num processo contínuo para o resto da vida. Uma alfabetização que supere a simples reprodução de conceitos científicos, sem significação, sentido e aplicação.

Defendemos a perspectiva de que o ensino de Ciências tem por objetivo apresentar conhecimentos científicos, bem como discuti-los, para compreender seus significados e sua aplicabilidade para melhor entender o mundo. Noutras palavras, volta-se para o desenvolvimento de conhecimentos a serem utilizados por cada sujeito em diferentes

$3>$ Referimo-nos aos estudos de Miller, que buscou definir alfabetização científica como a "[...] capacidade de ler, compreender e expressar opinião sobre assuntos de caráter científico" (MILLER, 1983, p. 30), constituindo-se como referência em estudos do campo. Soares (1985) que procurou estabelecer diferenças conceituais entre alfabetizar e letrar, trazendo reflexões históricas e teóricas para problematizar que ambos processos são indissociáveis, atribuindo a esse percurso de apropriação do sistema alfabético uma dimensão de diálogo com outras áreas do conhecimento. Hazn e Trefil (1995) que entendem alfabetização científica como aquela que envolve uma série de fatos, conceitos, vocabulários específicos, História e também Filosofia, abarcando o conhecimento científico para melhor entender os debates públicos sobre ciência e tecnologia. Ver também: Cagliari (1998), Krasilchik (1992) e Hurd (1998). contextos e de acordo com suas necessidades, nesse caso, visa à formação do cidadão.

Lorenzetti e Delizoicov (2001) destacam, ainda, que, nas práticas escolares, comumente, a ênfase volta-se para a alfabetização funcional, focando em um grande número de conceitos, muitas vezes descontextualizados e voltados para memorização. No entanto, para esses autores, amplia-se e aprimora-se o vocabulário científico das crianças por meio de uma aprendizagem contextualizada que permita a identificação dos significados desses conceitos e a interação entre ciência, tecnologia e sociedade.

$\mathrm{Na}$ linha do que defendem esses autores, entendemos ser de fundamental importância que ao ensino de Ciências seja atribuído um lugar nas práticas escolares da alfabetização desde a Educação Infantil. A ideia é a de promover experiências para atribuir sentido ao conhecimento científico, levantando hipóteses para que sejam confirmadas ou refutadas e, na mesma medida, ler/escrever textos de gêneros da ordem do narrar, do expor e do argumentar específicos do campo científico, como: relatórios, textos informativos, notas de divulgação científica, dentre outros.

Partimos da hipótese de que a provável visão cientificista dos estudantes, vinculada ao senso comum, pode ser superada através da alfabetização científica, em que a reflexão sobre o significado ético dos conteúdos e suas relações com a tecnologia e a sociedade 
podem propiciar a formação de cidadãos críticos e responsáveis. Por exemplo, a leitura de textos que problematizem a visão estereotipada do cientista como um profissional que atua exclusivamente em laboratórios pode ampliar o entendimento dos estudantes para a compreensão de que há cientistas em todas as áreas do conhecimento e que se faz pesquisa a todo tempo e em diferentes lugares.

Essa perspectiva de educação para as Ciências pode encontrar, no trabalho com as múltiplas linguagens, um apoio para a operacionalização do que chamamos de alfabetização científica. Essas linguagens representam o encontro do leitor com a literatura, a obra de arte, a fotografia, o cinema, com os textos que veiculam informações científicas com vocabulário que aproxima as discussões sobre temas científicos, promovendo o que aqui chamamos, em confluência com autores do campo, de alfabetização científica.

$\mathrm{Na}$ introdução deste texto, provocamos o leitor a pensar em questões complementares e por ora recuperamos duas delas para problematizar o que Lorenzetti e Delizoicov (2001) apontam sobre a circulação de textos nas escolas: a. como a escola poderia contribuir para o desenvolvimento de um pensamento sobre o que a criança aprende, considerando o percurso de compreensão?; b. Como os professores poderiam mediar a relação entre conhecimento científico e leitura crítica sobre os fatos, buscando uma formação leitora em que a criança estabeleça relações conceituais, realize inferências, dentre outras estratégias de compreensão? De um lado, o desafio de que a criança aprenda e compreenda o conhecimento científico. Do outro, o desafio de formar um leitor capaz de mobilizar diferentes estratégias leitoras, operando com conhecimentos de diferentes naturezas - o linguístico (as palavras que formam o texto), o extralinguístico (conhecimento de mundo) e o interacional (relação do leitor com o texto).

Dessa forma, podemos ir constituindo a formação de uma atitude científica a partir da interação do sujeito leitor com textos que dizem do humano. O processo de alfabetização científica, nesse sentido, pode ocorrer pela formação de um leitor que não apenas lê as informações contidas nos textos, mas as compreende por meio de questionamentos, observando, de forma curiosa, meandros do texto, identificando os posicionamentos dos autores e os valores que os cercam, distinguindo fatos de opiniões sobre os fatos, adotando, assim, uma posição crítica em relação às informações, reforçando a ideia de que a Ciência está em todos os lugares.

Para contribuir com essa busca por vencer desafios de uma educação para as Ciências que considere a formação de uma atitude científica, ter um professor que questione visões de Ciências dogmáticas e acríticas, atuando como mediador da relação entre senso comum e conhecimento científico, poderia apontar caminhos outros para a formação do leitor desde a Educação Infantil. Nesse sentido, pensar a formação de professores também se coloca como um desafio para o ensino de Ciências nos anos iniciais, considerando o papel da alfabetização científica para a formação dessa atitude científica. Para essa forma de alfabetizar cientificamente, faz-se mister uma relação de interação entre professor, estudante e conhecimento científico, na qual o papel do professor se configura como o de mediador dos conhecimentos prévios dos estudantes com a visão trazida pelo conhecimento científico. Nessa direção, é importante a atenção do professor como mediador da linguagem, seja ela verbal (oral e escrita), imagética, gestual, entre outras, porque é através dela que os estudantes terão contato com o conhecimento científico.

No tocante à formação de professores de Ciências, Carvalho e Gil-Pérez (2011, p. 18-20) propõem um quadro sobre o que devem "saber" e "saber fazer" tais professores, tomando por base "[...] a ideia de aprendizagem como construção de conhecimentos com as características de uma pesquisa científica e a necessidade de transformar o pensamento espontâneo do professor". Os referidos autores esclarecem que é óbvia a inviabilidade do desenvolvimento de tantos conhecimentos pelos professores, de maneira isolada. Entretanto, eles afirmam ser fundamental um trabalho coletivo em todo processo de ensino e 
aprendizagem, desde a preparação das aulas até o momento da avaliação, pautado pela inovação, pesquisa e formação permanente. Concordamos com esses autores no que se refere à necessidade da existência de trabalho docente coletivo, porque a interlocução entre os professores - não só da mesma disciplina escolar, mas entre os docentes de diferentes disciplinas e anos escolares - é imprescindível para a realização de um ensino que vise à construção do conhecimento em Ciências.

No sentido de fundamentar um pouco mais a incursão do tema da formação continuada de professores de Ciências, no âmbito da Academia, destacamos três pesquisas que apresentam como ponto em comum que deve haver um plano de trabalho em que sejam privilegiados: a. a autonomia docente; b. o trabalho em equipe; e c. a integração entre teoria e prática através da realização de pesquisa e de reflexão sobre a ação pedagógica ${ }^{4}$.

Selles (2002) realizou um importante estudo sobre um projeto de formação continuada para o desenvolvimento profissional desses professores, no qual discute diferentes dimensões desse desenvolvimento, destacando seus indicadores. Na visão dessa autora, os programas de formação continuada que valorizam a participação docente e reconhecem o seu papel multiplicador alimentam o processo de desenvolvimento profissional, desde que tais programas estejam baseados em dois eixos: a. pedagógico, para possibilitar a atualização e ampliação do conhecimento científico-educacional; e b. político-profissional, para a elaboração de estratégias que propiciem a reformulação das condições da profissão docente.

Por sua vez, Trivelato (2003, p. 63) analisou o Módulo de Ciências do Projeto de Formação em Serviço de Professores do II Ciclo do Ensino Fundamental, partindo da premissa de que "[...] tanto os alunos quanto os professores aprendem quando reconstroem ou reestruturam seus conhecimentos anteriores e que esse processo só se efetua quando é desencadeado por uma pergunta genuína ou por um problema de investigação”. Assim, para essa outra autora, os programas de formação de professores de Ciências devem englobar aprendizagens que passam pelos conceitos científicos e, também, pela Didática das Ciências, para que o objetivo da aprendizagem seja, de fato, alcançado. Para tanto, as aulas de Ciências devem ser pautadas por questões/problemas, que retomem conhecimentos anteriores. Através da vivência de aprendizagem pelos professores, estes possuem a possibilidade de se tornarem mais autônomos quanto à seleção e à organização do conteúdo, definindo os procedimentos de ensino. Concordamos com Trivelato ao concluir sobre a necessidade de o professor em formação continuada vivenciar sequências didáticas que trabalhem conceitos e metodologias que possam ser aplicadas junto aos alunos, sem a perspectiva de receituário, mas de autonomia do professor sobre a razão de sua escolha.

Nessa linha de concordância, trazemos a este texto os estudos de Gil-Pérez (1996, p. 74), que estabelece orientações didáticas em relação à estratégia e à estrutura adequadas para esse fim. Quanto à estratégia, esse autor indica como a mais produtiva aquela que insere o professor "na pesquisa dos problemas de ensino e aprendizagem de Ciências", tomando como base a prática pedagógica. Entretanto, esse trabalho de investigação precisa inicialmente ser dirigido e, paulatinamente, irem se formando "equipes autônomas de trabalho, vinculadas à comunidade de pesquisadores e inovadores na Didática das Ciências". Nessa concepção de ensino, o professor tem o papel fundamental de propiciar aos estudantes situações de sistematização de conhecimentos científicos, para promover um entendimento de que as Ciências não são apenas uma disciplina circundada ao âmbito escolar, mas parte do mundo, da vida, da realidade intra e extraescolar associadamente. Isso implica a promoção de estratégias metodológicas que aliem conceitos e procedimentos, tais como a observação, o registro, a descrição de fenômenos, a elaboração de

4 > Referimo-nos aos trabalhos de Selles (2002), Trivelato (2003) e Gil-Perez (1996). hipóteses, a avaliação dessas hipóteses e sua testagem por meio de experimentos, registros de resultados, entre outros. 
Uma sistematização que requer fazer escolhas metodológicas, como a pensada por Delizoicov e Angotti (1990), que se divide em três momentos pedagógicos: a problematização, a organização do conhecimento e a aplicação do conhecimento. Para o processo de problematização, é necessário que o professor compreenda as diversas demandas contemporâneas, perceba seu papel como agente de transformação e, consequentemente, estimule os estudantes, considerando diferentes tempos de aprendizagem, a perceberem, a discutirem e a buscarem soluções para a realidade social na qual estão inseridos. Em termos práticos, significa provocar a curiosidade epistemológica, ou seja, introduzir conceitos-chave por meio de questões geradoras, colocando em dúvida certezas e trazendo ao debate suas próprias experiências. A dimensão de organização do conhecimento implica compreender o papel do processo de sistematização para a apropriação do conhecimento científico, sendo a experimentação uma das possibilidades desse processo, assim como o acesso às múltiplas linguagens de forma reflexiva. O momento pedagógico de aplicação do conhecimento pode se dar através de um processo de avaliação diagnóstica tanto por meio do levantamento de hipóteses como por aferições diversas pelo contato com as diferentes fontes. Essas avaliações sobre o processo de compreensão geram novas problematizações que precisam ser sistematizadas.

Nessa concepção de ensino, o professor tem o papel fundamental de propiciar aos estudantes situações de sistematização de conhecimentos científicos, para promover um entendimento de que as Ciências não são apenas uma disciplina circundada ao âmbito escolar, mas parte do mundo, da vida, da realidade intra e extraescolar, associadamente. Isso implica a promoção de estratégias metodológicas que aliem conceitos e procedimentos, tais como a observação, o registro, a descrição de fenômenos, a elaboração de hipóteses, a avaliação dessas hipóteses e sua testagem por meio de experimentos, registros de resultados, entre outros. Uma sistematização que requer fazer escolhas metodológicas, como a pensada por Delizoicov e Angotti (1990), que se divide em três momentos pedagógicos: a problematização, a organização do conhecimento e a aplicação do conhecimento.

Para o processo de problematização, é necessário que o professor compreenda as diversas demandas contemporâneas, perceba seu papel como agente de transformação e, consequentemente, estimule os estudantes, considerando diferentes tempos de aprendizagem, a perceberem, a discutirem e a buscarem soluções para a realidade social na qual estão inseridos. Em termos práticos, significa provocar a curiosidade epistemológica, ou seja, introduzir conceitos-chave por meio de questões geradoras, colocando em dúvida certezas e trazendo ao debate suas próprias experiências. A dimensão de organização do conhecimento implica compreender o papel do processo de sistematização para a apropriação do conhecimento científico, sendo a experimentação uma das possibilidades desse processo, assim como o acesso às múltiplas linguagens de forma reflexiva. O momento pedagógico de aplicação do conhecimento pode se dar através de um processo de avaliação diagnóstica tanto por meio do levantamento de hipóteses, como por aferições diversas pelo contato com as diferentes fontes. Essas avaliações sobre o processo de compreensão geram novas problematizações que precisam ser sistematizadas.

Nessa premissa metodológica de sistematização dos conhecimentos científicos, o desafio é que as ações promotoras de aprendizagem desmistifiquem o método científico que tem sido relacionado com um saber rigoroso, técnico, neutro e preciso da investigação sobre o objeto que extrai um conhecimento categorizado como verdadeiro. Quando as pessoas afirmam que o mundo está confuso porque o que se disse ontem como verdade, hoje, já não é bem assim, estão exatamente falando de suas dificuldades para entender que algo que era considerado uma verdade científica anteriormente, passado o tempo e com os avanços do conhecimento, poderá não o ser mais. Um exemplo disso são as propriedades e os efeitos dos alimentos no organismo humano, que a cada estudo se renova, sendo apresentado pela mídia à população como algo fantástico ou usando a célebre frase "foi 
comprovado cientificamente”. Essa situação retrata a concepção de Ciências repleta de dogmas que está presente na sociedade, na qual o professor está inserido e, muitas vezes, compartilhando da mesma concepção de senso comum que precisa ser superada, trazendo diferentes pontos de vista sobre um determinado fato considerado cientificamente.

Por conseguinte, alfabetizar cientificamente os estudantes significa ajudá-los a construir uma concepção de Ciências que: a. modifica-se ao longo da História; b. não possui um único método científico para pensar o processo investigativo; c. utiliza-se da experimentação no ensino não para concretizar conceitos através da prova de veracidade da teoria, tampouco apenas para facilitar a aprendizagem, mas para desenvolver a relação entre o fazer e o pensar de modo investigativo, dialógico e reflexivo.

Nessa direção, consideramos a leitura, a partir do acesso a múltiplas linguagens, elemento central para a compreensão de conhecimentos científicos. Podemos, assim, afirmar que ler com compreensão possibilita a ampliação de conhecimentos que contribuem para o processo de alfabetização científica. Entendemos, portanto, que a formação de uma atitude científica requer que essa leitura observadora e questionadora considere: a. o contexto de circulação das informações científicas; $b$. o estilo dos autores pesquisadores; c. as informações sobre um mesmo tema veiculadas em outros contextos de circulação; d. a aproximação e/ou distanciamento das informações apresentadas pelas diferentes linguagens problematizadoras do conhecimento científico.

Pensar em uma proposta de trabalho para a formação da atitude científica aponta para a necessidade de que o professor não só domine os conteúdos dos anos/série pelos quais se responsabiliza, mas também apresente uma abertura à pesquisa constante, na perspectiva "crítico-reflexiva" (NÓVOA, 1992) em que ele possa refletir sobre sua prática e elaborar novos caminhos para organizar diferentes situações didáticas que ajudem o aluno a aprender.

Nessa perspectiva, o professor precisa ser indagador da própria prática pedagógica, considerando-a um objeto de pesquisa que, segundo Nóvoa (1992), seria a postura do professor reflexivo, crítico e pesquisador. Para esse autor, o diálogo entre os professores é fundamental para que a dimensão coletiva se sobreponha às práticas pedagógicas individuais e isoladas que em nada contribuem para a construção do conhecimento em Ciências, visto que tal construção coletiva é importante não só para a solução de problemas do cotidiano, como também para permitir aos indivíduos se tornarem cidadãos críticos em relação à sociedade.

Entendemos que o professor precisa ter então atitude científica, ou seja, estar atento ao desenrolar das atividades, mediando situações questionadoras de aprendizagem durante o processo de transposição didática (CHEVALLARD, 1991) ${ }^{5}$ das observações das ações sobre os objetos de construção dos conhecimentos científicos, pois, além de saber o conteúdo, o professor precisa saber como ensiná-lo e adotar uma postura investigativa.

O ponto fundamental da transposição didática encontra-se, de acordo com os estudos de Zanon e Freitas (2007), na ruptura com a concepção de que um bom estudante de Ciências seria aquele que, por exemplo, soubesse de cor a lista de raízes comestíveis, mas que passasse a ser aquele que, enquanto está se alimentando com mandioca (também conhecida como aipim ou macaxeira em outros estados do Brasil), se perguntasse se é uma raiz e qual o seu papel na pirâmide alimentar, questionando usos da raiz na alimentação, dentre outros fatores. Logo em seguida, soubesse tomar a iniciativa de procurar, em uma fonte adequada, as informações para responder as suas inquietações, assim como colocasse em diálogo suas descobertas.

Ao mesmo tempo em que estratégias metodológicas são propostas como possibili-

dades de organização dos tempos e espaços escolares para pensar o ensino de Ciências nos anos iniciais do Ensino Fundamental, há que se pensar no movimento de retomada do que foi estudado, através de uma prática avaliativa centrada na concepção de infância que concebe a criança em sua singularidade e na forma como poderá consolidar as aprendizagens do campo científico. O que as crianças podem aprender nas aulas de Ciências? Como 
possibilitar que essa aprendizagem seja observada, discutida, retomada, ressignificada? Esses são questionamentos que necessitam ser considerados no processo pedagógico de problematização, organização e aplicação do conhecimento científico no processo de (re) formulação de um currículo.

\section{Educar para uma atitude científica: discutindo uma proposta curricular}

A Constituição de 1988, em seu artigo 210, traz a necessidade de estabelecer "conteúdos mínimos para o ensino fundamental, de maneira a assegurar a formação básica comum e respeito aos valores culturais e artísticos, nacionais e regionais" (BRASIL, 1988, s/p). Na mesma linha, a Lei de Diretrizes e Bases da Educação Nacional (BRASIL, 1996), no artigo 26, parágrafo primeiro, estabelece a base nacional comum e a parte diversificada, que deve adequar-se à regionalidade, à cultura e à economia. Essas referências de base legal conduziram a estruturação de referências curriculares na busca pela garantia do direito de aprendizagem, concretizada pelos Parâmetros Curriculares Nacionais (PCN) (BRASIL, 2000), Diretrizes Curriculares Nacionais (DCN) (BRASIL, 2013) e, atualmente, pela Base Nacional Comum Curricular (BNCC) (BRASIL, 2018).

Nos PCNs, já se constatava uma preocupação em se traçarem diretrizes para a educação para as Ciências da Natureza, entendendo essa área do conhecimento como uma elaboração humana para a compreensão do mundo (BRASIL, 2000). O ensino dessa disciplina no referido documento estava organizado em quatro blocos temáticos propostos para o Ensino Fundamental, a saber: ambiente; ser humano e saúde; recursos tecnológicos; Terra e Universo. Nesse contexto, os blocos poderiam ser abordados observando o tempo de aprendizagem, respeitando os limites de abstração e apontando para a discussão sobre experiências vividas pelas crianças. No documento constavam as discussões e propostas que poderiam ser implementadas pelas escolas, dentro dos objetivos, conteúdos e critérios de avaliação das Ciências, observando especificidades do primeiro e segundo ciclos do Ensino Fundamental. A sugestão oficial do governo era que o eixo de transversalidade dialogasse com a proposta curricular do Ensino Fundamental por meio de temas geradores que interagissem com situações que emanassem do cotidiano dos estudantes.

As Diretrizes Curriculares Nacionais da Educação Básica, apesar de não definirem temas para a área de Ciências da Natureza, confluem com o que preconiza a Carta Magna (BRASIL, 1988), quando enfatizam que “[...] os conteúdos sistematizados que fazem parte do currículo são denominados componentes curriculares, os quais, por sua vez, se articulam com as áreas de conhecimento [...], [que] favorecem a comunicação entre os conhecimentos e saberes dos diferentes componentes curriculares" (BRASIL, 2013, p. 186), admitindo, nesse caso, que aquilo que é próprio de cada componente curricular constitua a base do currículo. As DCNs têm como uma de suas linhas fomentar orientações que contribuam para assegurar a formação básica comum nacional e, dessa forma, contribuir para a elaboração do currículo escolar (BRASIL, 2013).

Tanto os PCNs quanto as DCNs não são mais diretamente definidores das orientações curriculares oficiais. Todavia, o documento atual de referência curricular, BNCC, foi elaborado considerando essas orientações históricas do currículo em nosso país, o que pode ser observado pela permanência de elementos estruturantes do componente curricular de Ciências da Natureza, no caso em tela, permanecendo, assim, a busca pela implementação de um currículo que garanta o direito de todos à aprendizagem.

Como apontado na introdução deste texto, o currículo, entendido como território movente, é proposto aqui, para o ensino de Ciências, a partir de aspectos metodológicos, 
mediados por conceitos, cuja avaliação diagnóstica e trabalho sistemático podem contribuir para a formação de uma atitude científica, adquirida pela formação leitora observadora e questionadora.

A proposta curricular em tela apoia-se no diálogo com as referências curriculares citadas neste subitem - PCN, DCN e BNCC - e nos resultados das pesquisas realizadas na área do ensino de Ciências ${ }^{6}$. Esse cotejamento resulta na proposição de eixos que julgamos articuladores de uma formação para a adoção de uma atitude científica, considerando os sujeitos por quem a escola, ao assumir uma atitude de garantia do direito à educação, pode pautar suas escolhas. Trazemos, nesse sentido, o seguinte mapa curricular: a. proposição de campos do conhecimento científico; b. escolha de conhecimentos conceituais que podem concorrer para a compreensão dos campos do conhecimento; c. estabelecimento de objetivos de aprendizagem voltados para a compreensão dos conceitos elencados; $\mathrm{d}$. seleção de múltiplas linguagens que podem auxiliar na problematização dos conhecimentos conceituais elencados para cada etapa do processo de escolarização; e. adoção de estratégias de ensino que contribuam para a sistematização da formação leitora de um estudante alfabetizado cientificamente.

Os campos do conhecimento científico procuram apresentar princípios das três áreas que estruturam o componente curricular de Ciências da Natureza, a saber: Física, Biologia e Química. A título de exemplo, em diálogo com a BNCC, poderíamos apresentar os campos Matéria e Energia, Vida e Evolução e Terra e Universo como possibilidade de contribuir para uma organização curricular que conflua com a concepção apresentada neste texto. Isso porque tais campos representam possibilidades de inserção em princípios da área de Ciências da Natureza ${ }^{7}$. Se retomarmos as proposições dos PCN (BRASIL, 2000) - Ser humano e saúde, Recursos tecnológicos e Terra e Universo - esses campos propostos pelo documento atual respeitam essa construção histórica e a retomam ampliando a concepção.

No segundo eixo, chamado conhecimentos conceituais das Ciências da Natureza, os conceitos elencados para cada ano/série visam a contribuir longitudinalmente com a formação do pensamento científico. Tal fato implica a proposição de objetos do conhecimento na relação com objetivos de aprendizagem, o que possibilita uma certa flexibilidade para a escolha de conceitos próximos que possam atuar de forma mais efetiva na aprendizagem dos estudantes dos anos iniciais. Os conteúdos conceituais poderão ser propostos no currículo a partir de estudos sobre fenômenos, processos e situações que suscitam o domínio de conhecimentos científicos para a sua compreensão. Essa escolha precisa ser compartilhada com os pares da escola no sentido de garantir a ideia de conteúdo como

6> A tese intitulada Formação Docente e Centro de Ciências: estudo sobre uma experiência de formação continuada de professores de química, defendida em 2013, por Vania Fernandes e Silva, uma das autoras deste texto, vem contribuindo para a realização de ações de ensino, pesquisa, formação de professores e discussão curricular no Colégio de Aplicação João XXIII/UFJF.

$7>$ Em que pese o fato de termos críticas em relação à BNCC, em sua versão homologada em dezembro de 2018, entendemos que é necessário que a escola busque estabelecer um diálogo com a normativa curricular, avaliando possiblidades e limites de efetivação. Sendo assim, afirmamos que aqui consideramos os campos e que avançamos para outras questões não tratadas no documento para a proposição apresentada. meio para a formação de um pensamento sobre o componente curricular, marcando progressões ao longo das etapas de escolarização.

Para a seleção de múltiplas linguagens que contribuam para que os objetivos de aprendizagem sejam alcançados, é preciso compreender em que concepção essas escolhas se operam. Linguagem entendida em seu sentido plural e como elemento central às práticas metodológicas possíveis para a problematização das questões centrais dos conhecimentos conceituais científicos. A guisa de exemplificação, trata-se da leitura crítica de textos literários, músicas, teatro, filmes, textos informativos como notícias de jornais, revistas científicas voltadas para o público infantil, dentre outros. O que se pretende é trabalhar os significados dos conceitos científicos presentes nos diferentes gêneros textuais, promovendo leituras intertextuais. No caso dos objetivos de aprendizagem, é importante destacar que a ideia é a de que sejam pensados considerando a eleição dos conhecimentos conceituais específicos da área de forma a contribuir para a apropriação de um conhecimento científico. Simultaneamente, marcar a progressão, considerando especificidades do processo de desenvolvimento dos estudantes de cada ano/série, assim como elementos singulares que caracterizem os diferentes níveis da aprendizagem dos estudantes. 
O eixo estratégias de ensino fundamenta-se na prática investigativa a ser estimulada pela escola. Esse compromisso responde ao direito à educação quando possibilita uma reflexão em torno dos modos de produção do conhecimento científico, por requerer um estudo metodologicamente sistematizado. A meta é a aprendizagem de processos, práticas e procedimentos por meio de uma observação curiosa do contexto, a partir dos quais o conhecimento científico e a tecnologia são elaborados. Nesse sentido, as estratégias voltam-se para dois aspectos: desenvolver uma prática investigativa e testar modelos explicativos de um dado conhecimento. Essa formação crítica aponta para um percurso de sistematização em que é necessário que os estudantes questionem o objeto de investigação, identifiquem possíveis problemas, proponham e afiram hipóteses, argumentem e expliquem suas conclusões, planejem e realizem experimentos, analisem suas descobertas para buscarem outras informações que auxiliem na resolução de problemas práticos que envolvam conhecimentos das Ciências.

Ao tomarmos como referência o que propõe a mais recente orientação curricular - a BNCC -, cotejando com o percurso de pesquisa que vínhamos realizando, podemos trazer contribuições para a formação inicial e continuada de professores que entendem a relevância de se estruturar um currículo que atenda a aspectos teóricos e metodológicos.

\section{Considerações finais}

A Educação em Ciências enfrenta um desafio contemporâneo voltado para a construção de conhecimentos científicos que contribuam para a formação de cidadãos críticos. Para tanto, torna-se necessário romper com conceitos que lidam com as Ciências de forma descontextualizada da realidade global. É necessário, também, buscar novos caminhos nos quais a produção do conhecimento científico e a interação entre sujeitos e objetos favoreçam interlocuções que permitam a apropriação desses novos conhecimentos por toda a sociedade.

Foi isso que buscamos fazer neste texto: propor uma possibilidade outra de pensar o currículo, entendendo que essa ruptura é necessária, mas que há momentos em que não sabemos como fazê-la. Um currículo para Ciências nos anos iniciais do Ensino Fundamental, ao estimular o debate, cria contradições e desperta o desejo de encontrar respostas/conclusões que estejam no plano da compreensão.

Ao pensar na relevância de adotarmos uma concepção de ensino que considere singularidades do sujeito que aprende na garantia de que terá acesso a conhecimentos científicos historicamente constituídos, estaremos definindo no currículo um percurso de aprendizagem que considera o conteúdo como meio para a formação de um sujeito que compreende e questiona o mundo em que vive. A questão desafiadora debruça-se, a nosso ver, sobre a possibilidade de a escola buscar conhecer os interesses das crianças, provocar reflexões sobre questões investigativas que se relacionam com as situações cotidianas reveladas por meio de problemáticas desafiadoras, buscando, sobretudo, ir além das observações diretas, proporcionando espaços para esse dizer hipotético que precisará ser testado para ganhar consolidação ou ser negado, movimentando e, mais do que isso, modificando percursos anteriormente definidos. Saltos instituídos, talvez, de conhecimento científico em conhecimento científico, por pensar nos contrassensos e nos desvios de uma dada realidade numa perspectiva de interrogação e interação constante.

Para concretizar-se o objetivo de reformulação de um currículo para a compreensão do conhecimento científico pelo estudante, fazendo com que ele realize aprendizagens significativas, muito ainda é preciso avançar. Este trabalho pode ser considerado um ensaio, visto que o desenvolvimento de uma atitude científica requer a definição sobre como ensinar 
um determinado conceito. No processo de desenvolvimento da atitude científica pelos estudantes, através da apropriação dos temas centrais por meio de múltiplas linguagens, concluímos que propor a leitura de diferentes textos, que tenham significado para os estudantes, assim como proporcionar um trabalho de exploração e compreensão desses textos, é tarefa curricular. Noutras palavras, a proposição de currículo em constante modificação não gera instabilidade, pelo contrário, apresenta caminhos metodológicos ancorados em escolhas teóricas que dão suporte ao trabalho de formação de um "pensamento sobre".

Defendemos, neste texto, que o ensino de Ciências pode ser pensado na perspectiva de diálogo dos estudantes com situações cotidianas, analisando-as e interpretando-as através dos artifícios próprios dos conhecimentos científicos. Movimentos estes que podem encontrar, na ação do sujeito sobre o objeto do saber no qual se debruçam, a emersão de imagens significativas para construir sentidos outros para a escola.

\section{Referências}

BRASIL. Base Nacional Comum Curricular: Educação Infantil e Ensino Fundamental. Brasília: MEC/Secretaria de Educação Básica, 2017.

BRASIL. Constituição da República Federativa do Brasil, 1988. Brasília: Senado Federal, 1988.

BRASIL. Diretrizes Curriculares Nacionais Gerais da Educação Básica. Brasília: MEC/Secretaria de Educação Básica, 2013.

BRASIL. Ensino Fundamental de nove anos: orientações para a inclusão da criança de seis anos de idade. Brasília: Ministério da Educação, Secretaria de Educação Básica, 2007.

BRASIL. Parâmetros Curriculares Nacionais. Brasília, MEC/SEF, 1997.

CAGLIARI, Luís Carlos. A leitura nas séries inicias. In: Leitura: teoria \& prática. Revista semestral da associação de Leitura do Brasil, n. 12, ano 7, Campinas, 1998.

CARVAlHO, Ana Maria Pessoa; GIL-PÉREZ, Daniel. A formação de professores de Ciências. São Paulo: Cortez, 2011.

CHASSOT, Attico. Catalisando transformações na educação. Ijuí: Ed. Unijuí, 1993.

CHASSOT, Attico. Alfabetização científica: questões e desafios para a educação. 6. ed. Ijuí: Ed. Unijuí, 2014.

CHAUÍ, Marilena. Convite à Filosofia. São Paulo: Ática, 1998.

CHEVALLARD, Yves. La Transposición Didáctica: del saber sabio al saber enseñado. Argentina: Editora Aique, 1991.

DELIZOICOV, Demetrio; ANGOTTI, José André. Metodologia do Ensino de Ciências. São Paulo: Cortez, 1990.

FERREIRA, Rosângela Veiga Júlio; MICARELLO, Hilda Aparecida Linhares da Silva; BARBOSA, Begma Tavares. A complexidade dos textos como critério para a seleção de suportes que avaliam o construto leitura. Anais do $5^{\circ}$ Congresso Nacional de Avaliação em Educação: da Educação Básica à Educação Superior. 03-05 dez. 2018. Bauru: UNESP/FC/Departamento de Educação, 2018. Disponível em: http://conave.fc.unesp.br/cnv/anais/index.php?t=TC2018101548037. Acesso em: 08 dez. 2019.

HAZEN, Robert; TREFIL, James. Saber ciência. São Paulo: Cultura Editores Associados, 1995.

HURD, Paul DeHart. Scientific literacy: new mind for a changing world. In: Science \& Education. Stanford, USA, n. 82, 1998, p. 407-416.

KRASILCHIK, Míriam. Caminhos do ensino de ciências no Brasil. Em Aberto. Brasília, n. 55, 1992, p. 4-8.

KRASILCHIK, Míriam; MARANDINO, Marta. Ensino de Ciências e Cidadania. 2. ed. São Paulo: Editora Moderna, 2007. 87p.

LORENZETTI, Leonir; DELIZOICOV, Demetrio. Alfabetização científica no contexto das séries iniciais. Ensaio Pesquisa em Educação em Ciências. Belo Horizonte, v. 3, n. 1, p. 45-61, 2001. 
MIRANDA, Sonia Regina et al. Proposta Curricular da Rede Municipal de Juiz de Fora: documento preliminar de História. Juiz de Fora: Secretaria Municipal de Educação, 2010.

NÓVOA, Antonio. Os professores e sua formação. Lisboa: Dom Quixote, 1992.

SELLES, Sandra Escovedo. Formação continuada e desenvolvimento profissional de professores de ciências: anotações de um projeto. Ensaio, v. 2, n. 2, p. 1-15, dez. 2002.

SOARES, Magda Becker. As muitas facetas da alfabetização. In: Cadernos de Pesquisa. São Paulo, n. 52, 1985, p. 19 - 24.

TRIVELATO, Silvia Luzia Frateschi. Um programa de Ciências para Educação continuada. In: CARVAlHO, Ana Maria Pessoa. (org.). Formação continuada de professores: uma releitura das áreas de conteúdo. São Paulo: Pioneira Thomson Learning, 2003.

ZANON, Dulcimeire Volante; FREITAS, Denise de. A aula de ciências nas séries iniciais do ensino fundamental: ações que favorecem a sua aprendizagem. Revista Ciências \& Cognição. Rio de Janeiro, v. 10, p. 93-103, mar. 2007. 
